\title{
Further Mutational Changes in the Photosynthetic Pigment System of Rhodopseudomonas spheroides
}

\author{
BY MARY GRIFFITHS* \\ Biology Department, Larerence College, Appleton, Wisconsin, U.S.A.
}

(Receized 8 May 1961)

\begin{abstract}
SUMMARY
Two further groups of pigment mutants have been isolated from irradiated suspensions of the non-sulphur purple bacterium khodopseudomonas spheroides. Both contain the normal red carotenoid of the wild type, but in place of bacteriochlorophyll one group contains a derivative at the oxidation level of chlorophyll $a$, and the other a pigment at the oxidation level of protochlorophyll. Both these groups are non-photosynthetic. All attempts to produce stable photosynthetic mutants containing a pigment absorbing at the same wavelengths as chlorophyll $a$ failed, although transient photosynthesis seemed to occur on several occasions. The relationship of these mutants to the biosynthetic pathway of bacteriochlorophyll suggested by Granick is discussed.
\end{abstract}

\section{INTRODUCTION}

In a previous study of the pigments of the photosynthetic bacterium Rhodopseudomonas spheroides, several mutants were isolated which were blocked at different points in the biosynthetic pathway of carotenoids. Investigation of the pigments they accumulated threw some light on the normal mechanism of carotenoid synthesis in the wild type (Griffiths \& Stanier, 1956). One of the mutants isolated, which contained normal bacteriochlorophyll, excreted considerable amounts of different bacteriochlorophyll derivatives into the medium (Sistrom, Griffiths \& Stanier, 1956). These were analysed, but it was not clear whether they were compounds in the normal biosynthetic pathway of bacteriochlorophyll, or a variety of rather meaningless degradation products. In the present study, further mutants have been isolated; these show blocks in bacteriochlorophyll synthesis. The pigments they accumulate within the cell have been isolated and studied in an attempt to acquire more information about the normal biosynthetic pathway of bacteriochlorophyll.

\section{METHOIS}

Biological material and media. Rhodopseudomonas spheroides strain 2.4.1, obtained from the collection of Professor C. B. van Niel (Hopkins Marine Station of Stanford University), was the wild-type used as starting material for the production of mutants.

For growth on agar plates, a $1 \%(\mathrm{w} / \mathrm{v})$ solution of yeast extract (Difco Labora-

* Present address : Department of Zoology, University of Washington, Seattle 5, Washington, U.S.A. 
tories, Detroit, U.S.A.) in tap water was used. For growth in liquid culture, either aerobically or photosynthetically, a partially defined medium described by CohenBazire, Sistrom \& Stanier (1957) was used. Non-photosynthetic mutants were grown semi-acrobically, in partially filled Erlenmeyer flasks, in the dark, unless otherwise stated.

Isolation of mutants. The isolation of mutants, produced by ultraviolet irradiation of the wild-type, was described previously (Griffiths \& Stanier, 1956).

\section{Isolation and determination of the pigments}

Carotenoids. Washed organisms were extracted three times with an acetone + methanol mixture ( $7+2$ by vol.) which removed all of the pigments. The carotenoids were extracted from this mixture by means of an equal volume of light petroleum (b.p. 60-70 $0^{\circ}$. The light petroleum extract was washed with the acetone + methanol mixture and then with water, concentrated, and placed on a column of aluminum oxide, activity grade 2 (Fisher Scientific Company, New York). The column was developed with light petrolcum and acetone.

Bacteriochlorophyll derivatives. Washed organisms were extracted three times with $80 \%(\mathrm{v} / \mathrm{v})$ acetone in water. As this extracts some of the carotenoids, as well as the bacteriochlorophyll derivatives being investigated, the former were removed by addition of an equal volume of light petrolcum (b.p. $60-70^{\circ}$ ) in a separatory funncl. The green lower acetone phase which contained the bacteriochlorophyll derivatives was run off and extracted three times with light petroleum to remove traces of carotenoids. Dicthyl ether was then added to the acctone phase and the pigments transferred to the ether by the cautious addition of water. The ether phase was washed with water to remove residual acetone, concentrated, and placed on a sucrose column. The column was developed with an ether + light petroleum mixture $(2+3$ by vol.), and the pigment eluted from the column with ether. All spectra were determincd with a Beckman model l)U spectrophotometer.

\section{RESULTS}

The pigments of the wild-type organism have been deseribed previously. For purposes of comparison it is sufficient to recall that Rhodopseudomonas spheroides has three pigments in its photosynthetic apparatus: two carotenoids and bacteriochlorophyll. When the wild-type is grown under non-photosynthetic conditions, semi-aerobically in the dark, the in vivo absorption spectrum obtained is that shown in Fig. 1. In living organisms, the region of carotenoid absorption is between 450 and $575 \mathrm{~m} \mu$, the remaining peaks at $370,590 \mathrm{~m} \mu$ and between 800 and $900 \mathrm{~m} \mu$ being due to bacteriochlorophyll. When the pigments are extracted into organic solvents, there is a shift in the position and pattern of the long wavelength peaks in the spectrum of bacteriochlorophyll, the complex absorption between 800 and $900 \mathrm{~m} \mu$ being replaced by a single peak at $775 \mathrm{~m} \mu$ (Fig. 2 ).

In the present study, more than 20 mutants showing deranged chlorophyll synthesis were isolated. They fall into two main groups having pigments with long wavelength absorption maxima at about 625 and $660 \mathrm{~m} \mu$, respectively, in organic solvents (Fig. 2). They will be referred to as the 625 mutants and the 660 mutants, since it is not possible to distinguish between them on the basis of colour. When 
grown on agar plates, all the mutant colonies are of some shade of green, whereas the wild-type is red. The 625 mutants are in general yellower than the 660 mutants, but within each group there is considerable variation in colour, duc to differences in the ratios of the amount of carotenoid pigment to the amount of bacteriochlorophyll derivative present.

Figure 1 shows the absorption spectra of young organisms grown acrobically on agar plates in the dark. The organisms were treated for $10 \mathrm{~min}$. in a $9 \mathrm{KC}$ Ray theon sonic oscillator to decrease the scattering when the absorption spectra were determined. It has previously been found on many occasions that this treatment does not alter the position of the peaks in the in vivo spectrum. It can be scen that there were

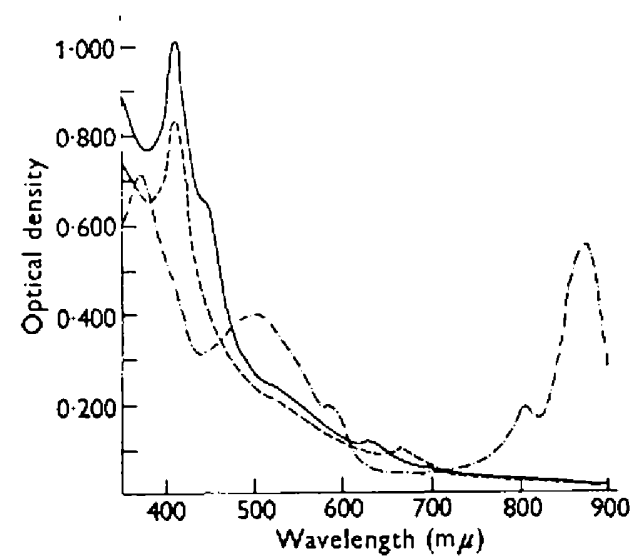

Fig. I

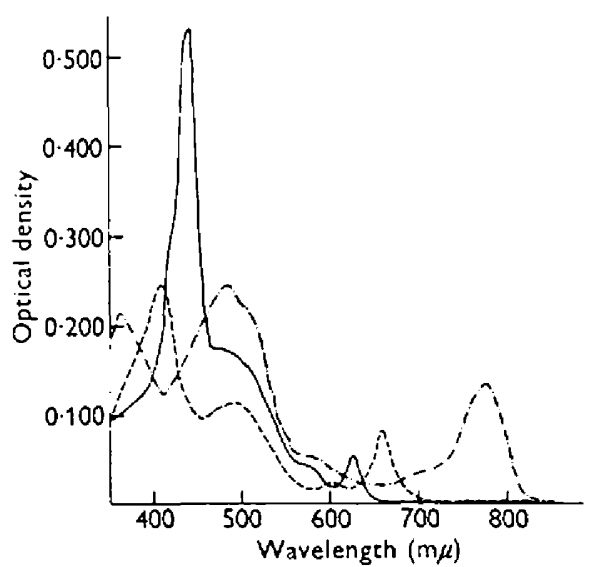

Fig. 2

Fig. 1. Absorption spectra of young Khodopseudomonas spheroides organisms grown semi-aerobically in the dark. The spectra of the 600 mutants (---) and of the 625 mutants (-) are compared with that of the wild type $(\cdots \cdots)$. The organism had been treated in a sonic oscillator for $10 \mathrm{~min}$. to decrease light scattering.

Fig. 2. Absorption spectra of acetone + methanol extracts of organisms grown semiacrobically in the dark. Wild-type of Rhodopseudomonas spheroides $(\cdots . .$.$) ; 660$ mutants $(\cdots)$ and 625 mutants $(-)$.

several striking changes in the spectra of the mutants compared with that of the wild-type grown under the same conditions. It is not possible from these spectra to say what kind of carotenoids are present in the mutants, but there was still considerable absorption in the region around $500 \mathrm{~m} \mu$, suggesting that carotenoids were present. With regard to bacteriochlorophyll absorption, there were radical changes. Both groups of mutants lacked the infrared peaks of the wild-type and the Soret peak at $370 \mathrm{~m} \mu$. Instead, the 660 mutants had a long wavelength maximum at $665 \mathrm{~m} \mu$, and a short wavelength peak at $410 \mathrm{~m} \mu$. 'The 625 mutants had a long wavelength maximum at $630 \mathrm{~m} \mu$, and a short wavelength peak at $412 \mathrm{~m} \mu$, with a pronounced shoulder at $440 \mathrm{~m} \mu$.

More information about the pigments in the mutants was obtained from their absorption spectra in organic solvents. Figure 2 shows the spectra obtained when organisms of typical mutants from each group were extracted with an acetone + methanol mixture $(7+2$ by vol.). The spectrum of the normal strain, similarly 
treated, is also given. In the 625 mutants there was usually a slight shoulder at $415 \mathrm{~m} \mu$, a main peak at $440 \mathrm{~m} \mu$ and a smaller peak at $625-630 \mathrm{~m} \mu$, due to bactcriochlorophyll derivatives, and a plateau around $475 \mathrm{~m} \mu$ in the region of carotenoid absorption. The 660 mutants all had a major peak at about $415 \mathrm{~m} / l$, and a long wavelength maximum at $660-662 \mathrm{~m} \mu$ due to a bacteriochlorophyll derivative. The greatest variation in this group was in the extent of absorption in the carotenoid region; but all showed a peak or plateau at about $490 \mathrm{~m} \mu$. In both groups of mutants the absorption due to carotenoids around $475 \mathrm{~m} \mu$ was quite like that found in the normal strain grown under the same conditions, but there were striking differences in the positions of the long wavelength maxima due to bacteriochlorophyll derivative absorption: from $775 \mathrm{~m} \mu$ for the normal strain to 660 and $625 \mathrm{~m} \mu$, respectively, for the mutant groups.

\section{Identification of pigments}

The two groups of mutants clearly did not contain any bacteriochlorophyll. To determine the nature of the bacteriochlorophyll derivatives, and of the carotenoids present, the pigments were separated by solvent partition and purified by chromatography as described in methods.

Carotenoids. The absorption spectrum of the main pigment found in the 660 mutants was identical with that of the normal red carotenoid found in the wild-type. There was also a trace of a second red pigment which absorbed towards longer wavelengths than the normal red. This pigment has been detected previously in dark red mutants of Rhodopseudomonas spheroides (Griftiths \& Stanier, 1956), but has not been obtained in sufficient quantities for purification. No yellow carotenoid was found, but none is produced in the wild-type, in any quantity, under aerobic conditions. The carotenoids of the 625 mutants were not purified by chromatography, but the spectrum of the crude carotenoid extract was the same as for the 660 mutants, and it can be safely concluded that the main carotenoid of both groups is the normal red pigment of the wild-type.

Bacteriochlorophyll derivatives. The spectra of the mutant pigments after purification by solvent partition and chromatography are shown in Fig. 3. For each mutant only one chlorophyll derivative was present in appreciable amounts. In determining the nature of these compounds, as far as is possible from the absorption spectra, the positions of the maxima and their relative heights are of importance (Stern \& Wenderlein, 1936; Stern \& Pruckncr, 1939; Rabinowitch, 1951). The position of the long wavelength maximum gives the level of oxidation of the compound, and the relative heights of the smaller pcaks indicate the presence or absence of magnesium.

660 mutants. The longest wavelength peak was at $660 \mathrm{~m} \mu$, a displacement of $115 \mathrm{~m} \mu$ to shorter wavelengths when compared with bacteriochlorophyll. The highest peak was at $450 \mathrm{~m} \mu$ with smaller peaks at $470,502,531,555$ and $603 \mathrm{~m} \mu$. Within the group there were very slight variations both in the positions of the peaks and in the relative heights of the peaks. Differences of the magnitudes encountered can be explaincd as due to slight differences in the nature of the side groups attached to the molecule. The position of the long wavelength maximum at $660 \mathrm{~m} \mu$ indicates that the pigment was not at the same oxidation level as bacteriochlorophyll, but at the higher oxidation level characteristic of chlorophyll $a$ and its derivatives. The 
presence of well defined peaks at 502 and $531 \mathrm{~m} \mu$ shows that the pigment molecule lacked magnesium and could not be chlorophyll $a$ (Rabinowitch, 1951, p. 628). Comparison with published data (Table 1 ) shows that the spectrum is very similar to that found by Smith \& Benitez (1955) for phcophytin a, which is chlorophyll $a$ with the magnesium removed, and even closer to that of a Chlorobium pheophytin prepared by Stanier \& Smith (1960) by removing the magnesium from the chlorophyll of green bacteria.

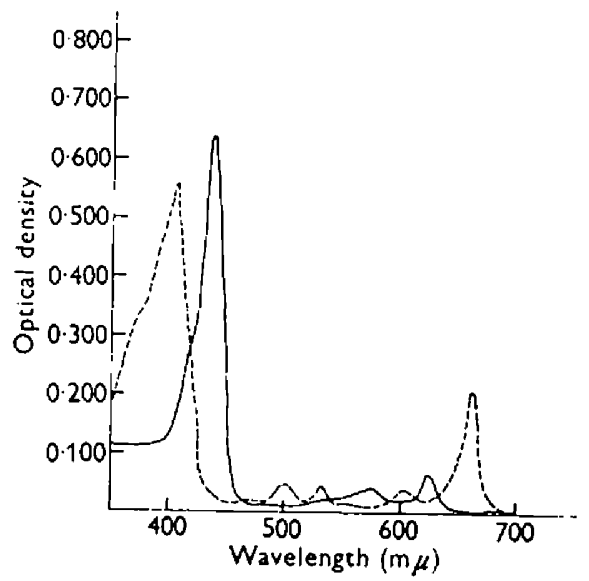

Fig. 3

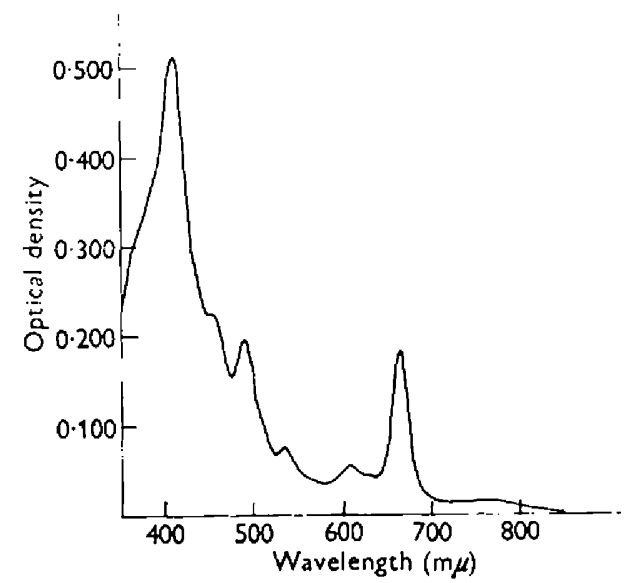

Fig. 4

Fig. 3. Absorption spectra of the pigments of the Rhodopseudomonas spheroides 660 mutants (-.) and of the 625 mutants (-) after partial purification by chromatography. In ethyl ether.

Fig. 4. Absorption spectrum of an acctone + methanol extract of cells of a mutant of Khndopseudomonas sphervides, lacking bacteriochlorophyll, which apparently grew under photosynthetic conditions.

Table 1. Absorption maxima and relative absorption of the 660 mutants of Rhodopseudomonas spheroides compared with those of pheophytin a (Smith \& Benitez, 1955) and of a Chlorobium pheophytin (Stanier \& Smith, 1960) in ether

\begin{tabular}{|c|c|c|c|c|c|c|c|}
\hline Pheophytin a & $\begin{array}{l}\max . \operatorname{m} \mu . \\
\text { rel. abs. }\end{array}$ & $\begin{array}{l}667 \\
48.4\end{array}$ & $\begin{array}{r}609 \cdot 5 \\
7 \cdot 4\end{array}$ & $\begin{array}{l}560 \\
2 \cdot 7\end{array}$ & $\begin{array}{l}534 \\
9.5\end{array}$ & $\begin{array}{l}505 \\
11 \cdot 0\end{array}$ & $\begin{array}{l}471 \\
3 \cdot 9\end{array}$ \\
\hline $\begin{array}{l}\text { Chlorobium pheo- } \\
\text { phytin (650) }\end{array}$ & $\begin{array}{l}\max . m \mu . \\
\text { rel. abs. }\end{array}$ & $\begin{array}{l}600 \\
49 \cdot 6\end{array}$ & $\begin{array}{l}605 \\
\quad 6 \cdot 6\end{array}$ & $\begin{array}{l}555 \\
2.5\end{array}$ & $\begin{array}{l}532 \\
9 \cdot 8\end{array}$ & $\begin{array}{r}503 \\
8.9\end{array}$ & $\begin{array}{l}470 \\
3 \cdot 1\end{array}$ \\
\hline 360 & $\begin{array}{l}\max . \operatorname{m} \mu \\
\text { rel. abs. }\end{array}$ & $\begin{array}{l}660 \\
37 \cdot 8\end{array}$ & $\begin{array}{l}603 \\
7 \cdot 0\end{array}$ & $\begin{array}{l}555 \\
2.7\end{array}$ & $\begin{array}{l}531 \\
8 \cdot 1\end{array}$ & $\begin{array}{l}502 \\
8 \cdot 8\end{array}$ & $\begin{array}{l}470 \\
3 \cdot 4\end{array}$ \\
\hline
\end{tabular}

625 mutants. For this group of mutants the spectrum of the partially purified pigment shown in Fig. 3 has a long wavelength maximum at $625 \mathrm{~m} \mu$; a furthes displacement of $35 \mathrm{~m} \mu$ to shortcr wavelengths when compared with the 660 mutants. The highest peak was at $437 \mathrm{~m} \mu$, with minor peals at 535 and $573 \mathrm{~m} \mu$. The position of the peak at $625 \mathrm{~m} \mu$ indicates that the pigment was at a still higher oxidation level than that of the 660 mutants, and was at the same oxidation level as protochlorophyll. The relative heights of the smaller peaks show that, in contrast to the 660 
mutants, the pigment of the 625 mutants did have magnesium in the molecule. Comparison with published spectral data (Koski \& Smith, 1948) shows that the 625 pigment is very closely related to protochlorophyll (Table 2).

Table 2. A comparison of the wavelengths and relative intensities of the absorption maxima of protochlorophyll (Koski \& Smith, 1948) and the 625 mutants of Rhodopseudomonas spheroides in ether

$\begin{array}{llrrrr}\text { Protochlorophyll } & \max . \operatorname{In} \mu & 623 & 571 & 535 & 432 \\ & \text { rel. intensity } & 2 & 3 & 4 & 1 \\ 625 \text { mutants } & \max . \operatorname{m} \mu & 624 & 573 & 535 & 437 \\ & \text { rel. intensity } & 2 & 8 & 4 & 1\end{array}$

\section{Biological abservations}

Stability of mutants. Both groups of mutants were unstable in several respects. There was frequent loss by death on slopes for no obvious reason. In all the mutants studied there was a progressive loss of pigment with time, which made it impossible to conduct all the work on any one mutant. When put under photosynthetic conditions in agar stabs or liquid culture, all the mutants, with a single exception, initially reverted to the wild-type, some more readily than others. IIowever, two mutants examined more than three years after their isolation were found to have lost completely their original capacity to revert to the wild-type.

Photosynthetic ability of mutants. No evidence of any photosynthetic ability in the 625 group of mutants was obtained, but work with this group was minimal. The results with the 660 groups of mutants were less clcar-cut. The carliest mutant of this type was isolated in 1945 (UV 47); it gave rise to colonies of a pale brown-green colour. When first isolated, it was extremcly unstable under photosynthetic conditions; subsequent plating produced colonics of a great varicty of colours, from almost colourless, to dark red, with several green and tan, as well as the normal brown-green. In a stab it usually showed light growth along the length of the stab, rather than centres of reversion. This suggested limited photosynthetic ability, but plating of organisms from such a stab invariably showed some wild-type colonics, so the rcsult was inconclusive.

In another experiment mutant UV 47 was grown semi-acrobically in the dark, and while in the exponential phase of growth was transferred to closed tubes in the light. Forty-cight hours later the tubes showed a dense growth which was bright green: the organisms were green and the medium was green, whereas with the wildtype the organisms are red and the medium cither coloul less or pink under these conditions. The spectrum of an acetone + methanol extract of organisms showed that most of the pigment present was of the $660 \mathrm{~m} \mu$ kind, with only traces of bacteriochlorophyll, absorbing at $760 \mathrm{~m} t$, due to a f('w reverted organisms (Fig. 4). The major photosynthetic growth had apparently been duc to mutant type organisms, but the result was again inconclusive because of the presence of some reverted organisms. Further experiments, designed to obtain quantitative results, fuiled since the mutant was soon unable to grow at all under photosynthetic conditions. $\Lambda$ similar transient ability to photosynthesize was found in two other mutants of the 660 groups. 


\section{DISCUSSION}

During this and previous investigations, groups of mutants have been isolated which show changes in pigment synthesis. These fall into five main groups which are summarized in Table 3, which shows the nature of the pigments they contain and the photosynthetic ability of the members of each group. 'This does not exhaust the theoretical possibilities. No mutant has been found from which both carotenoid and their colourless precursor phytoene are absent, but in which bacteriochlorophyll is prescnt. This may be an impossible combination from a mathematical point of view, as bacteriochlorophyll apparently occurs only in chromatophores, and carotenoids or their precursors appear to be necessary components of these structures. Nor has a group of mutants been found in which a bacteriochlorophyll precursor is present but carotenoids absent. This might be for the same reason, or perhaps two mutations are required for such a change. In this comnexion the last group of mutants is of interest in that the loss of all pigments has apparently been brought about by a single mutation.

In the wild-type bacteriochlorophyll precursors have not been detected in the cells by the methods used. Blocked mutants, which presumably accumulate the precursor formed immediately before the block, are therefore useful in indicating biosynthetic pathways. It was hoped that the two new groups of mutants isolated might throw light on the biosynthetic pathway of bacteriochlorophyll.

Granick (1951) worked out a scheme, hased on his work on the green alga Chlorella, for the major features of the synthesis of green plant chlorophyll. He suggested that bacteriochlorophyll fits into the scheme as follows:

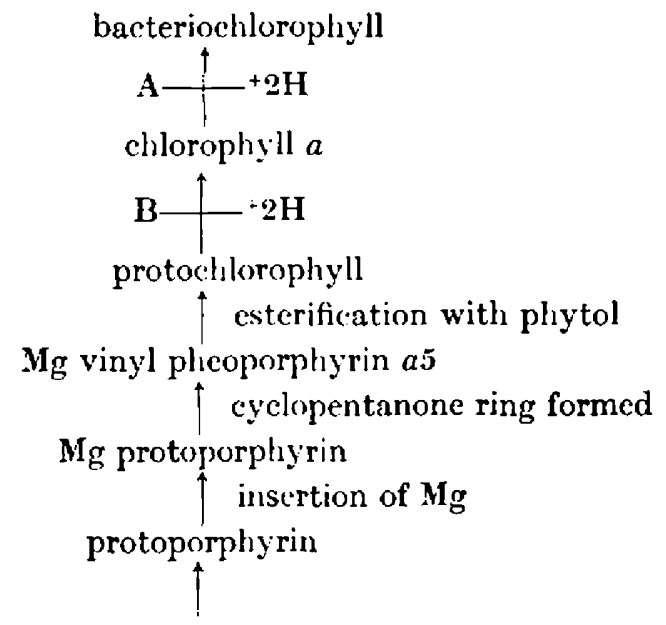

The structure of bacteriochlorophyll is known, but its position as the terminal molecule in such a biosynthetic pathway is mainly speculative and based on chemical reasoning. The two immediate precursors of bacteriochlorophyll, according to this scheme, would be chlorophyll $a$ and protochlorophyll, and these compounds might be expected to accumulate in mutants blocked at $A$ and $B$ respectively. The pigment of the 660 mutant of Rhodopseudomonas spheroides is clearly not chlorophyll $a$ although it is a related compound at the sume oxidation level as chlorophyll $a$. Likewise, the pigment of the $\mathbf{6 2 5}$ mutant of $R$. spheroides is not protochlorophyll, 
although it is a very closely related compound at the same oxidation level. The difficulty in interpretation arises from the fact that although the 625 mutant pigment contains magnesium (as would be expected from Granick's scheme since it should be inserted relatively carly in the biosynthesis of bacteriochlorophyll) the 660 pigment lacks magnesium and cannot be the precursor of bacteriochlorophyll. Perhaps in the 660 mutants the molecule occurring in the cell has, in fact, a magnesium atom in it, but is unstable during extraction; more subtle chemical extraction methods might reveal this. One can conclude only that pigments at oxidation levels consistent with Granick's scheme have been found. However, the fact that the 660 pigment resembles the pheophytin from Chlorobium chlorophyll even more closely than pheophytin from chlorophyll $a$ suggests that the former may be the actual precursor of bacteriochlorophyll. In this case, the terminal stages in bacteriochlorophyll synthesis would proceed by steps parallel to, but not identical with, those for chlorophyll $a$.

Table 3. The pigments contained in groups of mutants obtained by irradiation of Rhodopseudomonas spheroides

\begin{tabular}{|c|c|c|c|}
\hline $\begin{array}{l}\text { Mutant } \\
\text { group }\end{array}$ & Bacteriochlorophyll & Carotenoids & $\begin{array}{c}\text { Photosynthetic } \\
\text { ability }\end{array}$ \\
\hline $\mathbf{I}$ & Normal & $\begin{array}{l}\text { Present, but different from } \\
\text { wild-type }\end{array}$ & Present \\
\hline II & Normal & $\begin{array}{l}\text { Absent, but colourless pre- } \\
\text { cursor phytoene, present }\end{array}$ & $\begin{array}{l}\text { Present under anaerobic } \\
\text { conditions }\end{array}$ \\
\hline III & $\begin{array}{l}\text { Absent, but } 660 \text { or } 625 \\
\text { m } \mu \text { dervative of bucterio- } \\
\text { chlorophyll present }\end{array}$ & Normal & None or doubtful \\
\hline IV & Absent & Normal & None \\
\hline $\mathbf{v}$ & Absent & Absent & None \\
\hline
\end{tabular}

Granick (1957) suggested that in the evolution of photosynthetic pigments the precursors of the current pigments were at one time the functional light absorbers for photosynthetic reactions. They ceased to have this role when they gave up their positions as terminal members on the biosynthetic pathway, but he suggested that ecrtain vestigial capacities might remain. During the present work the question arose as to whether or not any of the 660 mutants of Rhodopseudomonas spheroides could photosynthesize. It was not at first realized that the extracted pigment of the 660 mutants contained no magnesium, or experiments to try to force photosynthetic growth would not have been attempted. It seems impossible to explain the dense growth of one 660 mutant (UV 47), anacrobically in the light, except on the basis of a transient capacity to photosynthesize. Onc possibility is that a magnesium containing pigment, closely related to chlorophyll $a$, is formed by at least some of the 660 mutants, but is unstable in the cell and accumulates for only a short time.

This work was supported by a grant from the National Science Foundation. 


\section{REFERENCES}

Cohgn-Bazire, G., Sistrou, W. R. \& Stavifr, R. Y. (1957). Kinetic studies of pigment synthesis by non-sulfur purple bacteria. .I. cell. comp. I'hysiol. 49, 25.

Granick, S. (1951). Biosynthesis of chlorophyll and related pigments. Annu. Rev. Hl. Physiol. 2, 115.

Granick, S. (1957). Speculations on the origins and evolution of photosynthesis. Proc. nat. Acad. Sci., Wash. 69, 292.

Griffitris, M. \& Stavier, R. Y. (1956). Some mutational changes in the photosynthetic* pigment system of Rhodopseudomonas spheroides. J. gen. Microbiol. 14, 698.

KoskI, V. AI. \& SMrтi, J. H. C. (1948). 'The isolation and spectral absorption properties of protochlorophyll from etiolated barley seedlings. J. Aner. chem. Soc. 70 , 3.558.

Ranixowitcin, E. I. (1051). Photosynthesis and Related Processes, vol. 2, part I. New York: Interscience l'ublishers.

Sistrom, W. R., Griffiths, M. \& STanier, R. Y. (1956). A note on the porphyrins excreted by the blue-green mutant of Rhodopseudomonas spheroides. I. cell. comp. Physiol. 48, 459.

Sirti, J. H. C. \& Benitez, A. (1955). Chlorophylls : analysis in plant materials. Moderne Methoden der Pflanzenanalyse, 4, 142. Berlin: Springer-Verlag.

Staien, K. Y. \& SiIth, J. II. C. (1960). The chlorophylls of grcen bacteria. Biochim. biophys. Acta, 41, 478.

Stern, A. \& Weniserleis, If. (1936). U'ber die Lichtabsorption der Porphyrine. Z. physs. Chem. A, 176,81 .

Stern, A. \& Prucknkr, F. (1939). Lichtahsorption einiger Derivate des Bacteriochlorophylls. Z. phys. Chem. $\Lambda, 185,140$. 